\title{
Differences in the expression of leptin receptors on bone marrow and peripheral blood cells
}

\author{
ELŻBIETA GÓRSKA, MARIA WĄSIK
}

Department of Laboratory Diagnostics and Clinical Immunology of Developmental Age, Medical University of Warsaw, Warsaw, Poland

\begin{abstract}
Leptin plays an important role as a modulator of immune response and hematopoiesis being engaged equally in innate and acquired immune response and influenced stem cells differentiation in bone marrow. The effective leptin action requires the expression of specific receptors on the surface of cells. In this study we examined leptin concentration in 42 samples of bone marrow and 83 samples of peripheral blood plasma. Leptin receptor expression on bone marrow nucleated cells and mature peripheral blood leukocytes were studied using flow cytometric method. Cell phenotyping was performed in a group of 39 healthy children who were free from hematological malignancies and immunological disorders. $O B-R$ was identified on membrane of stem cells $(C D 34+), T(C D 2+, C D 5+, C D 7+, C D 4+, C D 8+)$ and $B(C D 19+, C D 22+)$ cells, monocytes (CD4+, CD14+) and granulocytes (CD13+, CD33+).

The percentage of stem cells with $O B-R$ expression was lower than cells CD33/CD13/OB-R positive in bone marrow. The percentage of $O B-R+$ granulocytes was significantly lower in comparison to $O B-R+$ monocytes. However, in bone marrow and peripheral blood, the percentages of monocytes and granulocytes were higher than $O B-R$ positive $T$ and B-lymphocytes. In bone marrow and peripheral blood significantly more CD2CD8 cells expressing leptin receptor in comparison to CD2CD4 was observed. Almost 2.5-fold higher concentration of leptin was observed in blood plasma in comparison to bone marrow.

The percentage of $O B-R+$ monocytes and granulocytes in bone marrow and peripheral blood were on comparable level. In this two tissues differ $O B-R$ distribution was observed on $T$ and $B$ cells. Presented results may suggest the existence of some regulator influence of leptin concentration on expression of leptin receptor on lymphocytes in studied compartments.
\end{abstract}

Key words: leptin, leptin receptor, bone marrow, peripheral blood.

(Centr Eur J Immunol 2012; 37 (4): 332-337)

\section{Introduction}

Leptin is the most abundant adipocytokine produced by adipocytes in white adipose tissue cells, endothelial cells, $\mathrm{T}$ lymphocytes, bone marrow stromal cells and even platelets [1]. Discovered by Fredmann [2] in the early 90's, leptin has been recognized as an important regulator of energetic balance and body mass [3]. Recently published studies identified an important feedback between metabolism and immune system. Now, it is generally agreed that leptin plays an important role as a modulator of immune response and hematopoiesis $[1,4,5]$. It was documented that leptin in combination with another cytokines is able to induce development of myeloid and erythroid cell lineages. This influence is determined by anatomical relationship between adipose and lymphoid tissues [1, 6]. Lymphoid cells remain in intimate contact with adipose tissue in various anatomical locations such as mesenteric and omental fat tissue, lymph nodes surrounded by adipose tissue as well as in bone marrow where lymphoid cells may come in contact with adipocytes that supply fatty acids for lymphocytes 
proliferation. Moreover, the cells involved in the development of inflammatory response such as monocytes and macrophages were found in white adipose tissue along with NK cells and T and B cells [6].

The effective leptin action on hematopoietic and immune systems requires the expression of specific receptors on the surface of cells of both systems as well as the appropriated interaction between the ligand and the receptor $[5,7,8]$. Immediate vicinity of leptin-synthetizing cells and cells expressing leptin receptors creates substantial microenvironment necessary for development and maturation of blood cells $[6,8,9]$. The leptin receptor (OB-R) shares a homology with class I cytokine receptors and possesses the common signal transducing components for interleukin 6 (IL-6)-related family of cytokines [10]. Therefore, leptin after receptor ligation is able to modulate function of cells involved in the immune response. However, only one of the six recognized isoforms of the receptor (OB-Ra-f) exerts biological effects in immune and hematopoietic systems. These effects are mediated through the full-length transmembrane domain of the OB-R (OB-Rb). Signal released after binding of leptin to $\mathrm{OB}-\mathrm{Rb}$ stimulates the JAK/STAT-pathway and evokes intracellular phosphorylation processes. It is the main signaling pathways utilized by leptin to exert its cellular effects $[11,12]$.

In contrast to the studies of serum leptin concentration that are performed as routine diagnostics in patients with metabolic disorders, the assessment of leptin receptors on cells belonging to immune system are performed very seldom. In research reports, leptin receptor was evaluated on cell lines using histological or molecular methods and results obtained from studies of human blood cells were equivocal by reason of different methods applied [13-15].

Therefore, in this study we examined leptin receptor expression on immature and mature bone marrow nucleated cells and mature peripheral blood leukocytes. We want to check if passing of cells from bone marrow to periphery changes surface expression of OB-R and to evaluate OB-R expression in relation to leptin level in bone marrow and blood plasma. Our study was performed using flow cytometric technique and monoclonal antibodies against $\mathrm{T}$ and $\mathrm{B}$ cells, monocytes, granulocytes, stem cells and OB-R.

\section{Material and methods}

\section{Patients}

Phenotype of nuclear cells in bone marrow and peripheral blood was determined in a group of 39 healthy children (16 boys, 13 girls) aged 1.5-17. These children were referred to the Hematology Department and diagnosed to have benign hematological disorders (anemia, trombocytopenia). They were free from hematological malignancies and immunological disorders. Samples of bone marrow were taken after ilium puncture and transferred into tubes with
Parker medium supplemented with EDTA. Peripheral blood (1-2 ml) was drawn from cubital vein into tubes with EDTA. Samples of the bone marrow and peripheral blood remaining after routine laboratory examinations were used to isolate plasma and nuclear cells.

The assessment of leptin concentration was performed in 42 samples of bone marrow plasma and 83 samples of peripheral blood plasma. Body mass index of the studied patients was within normal range $\left(15.2-18.4 \mathrm{~kg} / \mathrm{m}^{2}\right)$.

\section{ELISA test}

A commercial immunoenzymatic kit to detect leptin (Quantikine Human Leptin, R\&D, Minneapolis, USA) was used. The test is based on a solid double antibody sandwich ELISA. Serum and bone marrow supernatants were added to microwells precoated with antibodies against leptin. All samples were assayed in duplicates. In the positive cases, antigen-antibody complex reacted with peroxidase-labeled antihuman $\mathrm{IgG}$ conjugate. Using $\mathrm{H}_{2} \mathrm{O}_{2} / \mathrm{TMB}$ as a substrate, the enzymatic activity of peroxidase was measured at $450 \mathrm{~nm}$ with the use of automated reading system Stat Fax 2100 (ALAB, Warsaw, Poland). Standards were provided for the generation of a semi-logarithmic reference curve, which all the results were referred to.

\section{Cell phenotyping}

The assessments of membrane expression of OB-R and the determination of bone marrow cells phenotype were performed using flow cytometry method (Cytometer FC 500, Beckman Coulter, USA). Granulocytes and lymphocytes from bone marrow cells and peripheral blood were isolated on density gradient. $2 \mathrm{ml}$ Histopaque ${ }^{\circledR}$ (Sigma Aldrich, $\mathrm{CO}$, USA) with relative density $\mathrm{d}=1.077 \pm 0.001 \mathrm{~g} / \mathrm{cm}^{3}$ was put on $3 \mathrm{ml}$ Histopaque ${ }^{\circledR}$ with $\mathrm{d}=1.115 \pm 0.002 \mathrm{~g} / \mathrm{cm}^{3}$ and then $5 \mathrm{ml}$ of appropriate tissue diluted with $0.9 \% \mathrm{NaCl}$ $(2: 1)$ was carefully added. Tubes were centrifuged $25 \mathrm{~min}$ at $2700 \mathrm{rpm}$ and two layers of the cells (granulocytes and lymphocytes) were collected separately and washed with $0.9 \% \mathrm{NaCl}$ three times. OB-R receptor was stained according to indirect immunofluorescence method using murine monoclonal IgG2A antibody against human leptin receptor manufactured by R\&D Systems and secondary FITC-conjugated AffiniPure Goat Anti-Mouse IgG manufactured by Jackson ImmunoResearch Laboratories, Inc. Monocytic cells lineage was identified using anti CD4 and CD14 antibodies, while granulocytic lineage was identified with anti CD13 and CD33 antibodies. Stem cells were identified with anti-CD34 monoclonal antibody. Always as first was performed procedure of OB-R staining. After washing, staining with monoclonal antibodies anti-CD2, CD5, CD7, CD4 and CD8 for T cells and anti CD19 and CD22 for B cells were carrying out. The antibodies were conjugated with FITC or PE that allow double staining. All tests were accompanied with suitable isotype controls. 
A

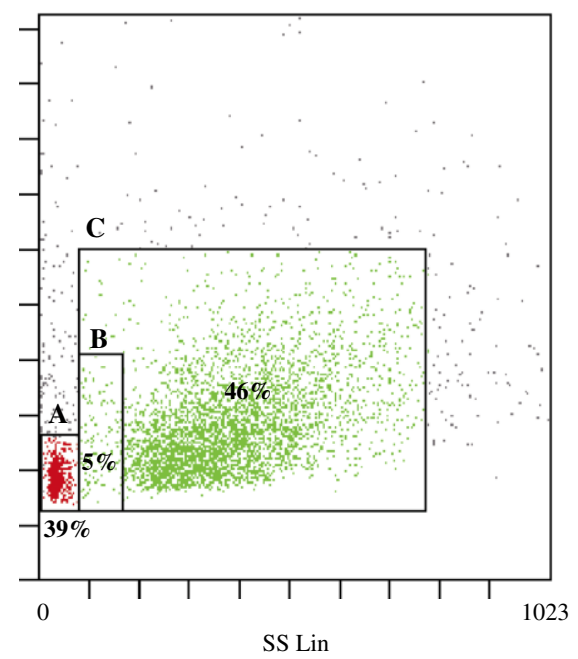

C

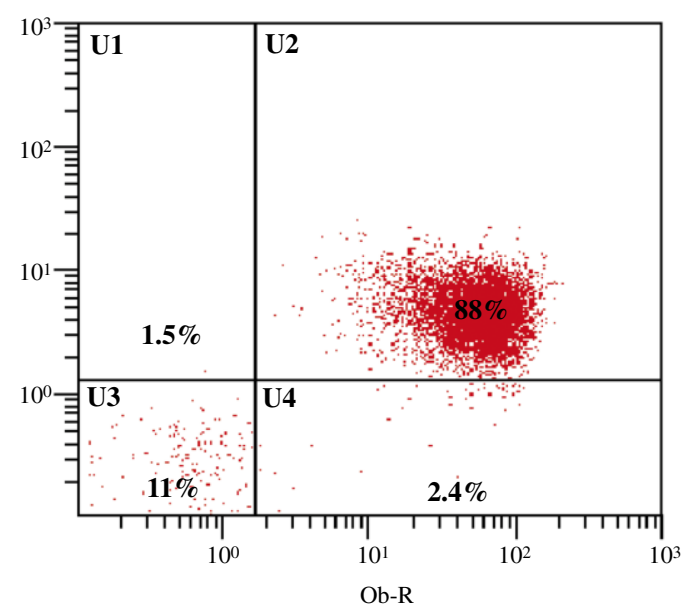

\section{Statistical analysis}

Statistical analysis was performed using Statistica v. 7.1 and Excel 2007 (Microsoft) software. As distributions of the studied parameters were not normal, nonparametric tests for independent samples were performed. The results were shown for median values $\left(Q_{1}-\right.$ first quartile, $Q_{3}-$ third quartile). Mann-Whitney $U$ test was used to calculate significance of differences between two groups. The value was considered statistically significant when $p \leq 0.05$.

\section{Results}

As shown in Fig. 1A and B bone marrow and peripheral blood before nuclear isolation contained electronically differentiated populations of polymorphonuclear cells and mononuclear cells. Figure 1C illustrated assessment of OB-R expression on blood granulocytes.

In bone marrow and peripheral blood taken from children without neoplastic disease in hematopoietic and lymphoid systems, the percentages of nuclear cell distribution

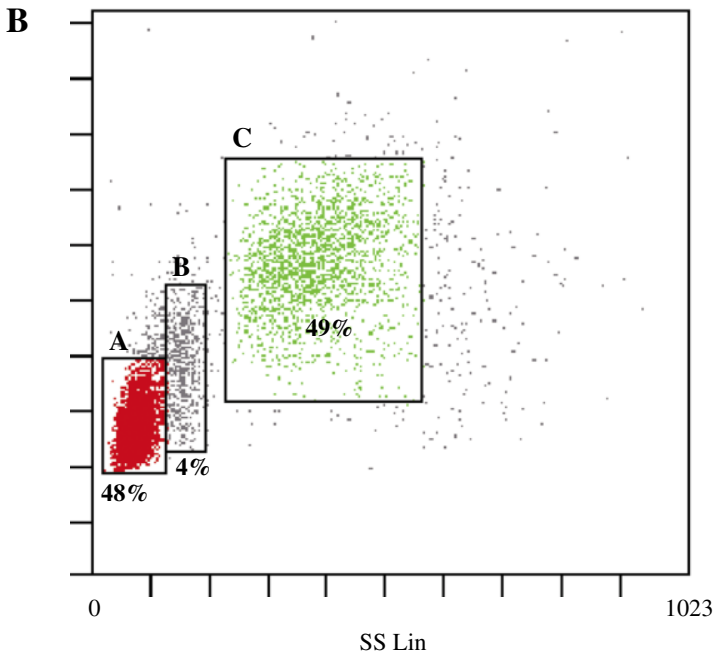

Fig. 1. Electronically differentiation according forward scatter (FS) vs. side scatter (SS) population of bone marrow cells (A) and peripheral blood leukocytes (B). Percentage of mononuclear cells (lymphocytes - gate A and monocytes gate B) and granulocytes (gate C) are given in cytograms. Cytogram $\mathrm{C}$ shows granulocytes isolated from peripheral blood and stained with anti-CD13/CD33 (FL2) and mouse anti OB-R monoclonal antibodies. Goat antibody against mouse IgG conjugated with fluoresceine (FL1) was used as the secondary antibody. Area U1 contained CD13/33+Ob-R-cells; area U2 contained double positive cells: CD13/33+OB-R+ and in $\mathrm{U} 3$ area are cells double negative. In $\mathrm{U} 4$ area are another cells presented after isolation that are $\mathrm{Ob}-\mathrm{R}+$

in the both tissue are shown in Table 1. Percentages of cells CD33+CD13+ and CD14+CD4+ was found very similar in the both tissue but significant differences were distributed among T and B lymphocytes. Peripheral blood contain 2.5 times more $\mathrm{T}$ than $\mathrm{B}$ cells, in contrast in bone marrow percentage of B cells is significantly higher. These results were obtained on the basis of flow cytometric assessment of these four populations before nuclear cell isolation (Table 1). Total number of cells expressing OB-R was comparable in the both tissues as well as is similar high percentages of OB-R positive granulocytes (CD33+CD13+) and monocytes (CD14+CD4+) and CD2CD4 T cells (Table 2). In bone marrow were higher percentages of lymphocytes $\mathrm{T}$ $(\mathrm{CD} 2+\mathrm{CD} 5+\mathrm{CD} 7+\mathrm{OB}-\mathrm{R}+)$ and subpopulations $\mathrm{CD} 2+$ $\mathrm{CD} 8+\mathrm{OB}-\mathrm{R}+$ than in peripheral blood, in contrast to lymphocytes $\mathrm{B}(\mathrm{CD} 19+\mathrm{CD} 22 \mathrm{OB}-\mathrm{R}+)$ presented in higher percentage in peripheral blood (Table 2).

The highest percentage of OB-R+ cells was found in population of monocytes. In the both tissue they were on comparable level like as OB-R+granulocytes (Table 2). 
However, about $50 \%$ of stem cells in bone marrow expressed leptin receptor but this percentage was significantly lower in comparison to OB-R positive monocytes and granulocytes (Table 3).

Moreover, in bone marrow and peripheral blood, percentages of $\mathrm{T}$ and $\mathrm{B}$ cells $\mathrm{OB}-\mathrm{R}+$ were significantly lower than CD33+/CD13+Ob-R+ and CD14+/CD4+ Ob-R+cells (Tables 2 and 3).

In bone marrow and peripheral blood significantly more CD2CD8 cells expressing leptin receptor in comparison to CD2CD4 (Tables 2 and 3) was observed. Statistical analysis of OB-R+ T lymphocytes subpopulation demonstrated that in peripheral blood the number of $\mathrm{CD} 2+\mathrm{CD} 8+\mathrm{OB}-\mathrm{R}+$ falls down significantly (Table 2 ) and the population of OB$\mathrm{R}+\mathrm{B}$ lymphocytes increased (Table 2) in comparison to bone marrow.

Leptin concentration in bone marrow and peripheral blood plasma is shown in Table 4. Almost 2.5-fold higher concentration of leptin was in blood plasma in comparison to bone marrow. The difference was statistically significant $(p<0.0001)$.

\section{Discussion}

Leptin, a major adipocytokine, functions simultaneously as a hormone and cytokine. It is produced in the adipose tissue in response to nutritional status and acts by binding to specific OB-R receptor. OB-R expression was found on cells belonging to innate and adaptive immune system [16] including human NK cell lineage [8], immature and mature dendritic cells $[17,18]$ and peripheral blood leukocytes $[7,8,19,20]$. We have found high total number of OB-R positive cells that were on comparable level in cells derived from bone marrow and peripheral blood but $\mathrm{OB}$ receptor distribution between different populations was different. In both studied tissues, the highest number of OB-R expressing cells was found in monocytes and granulocytes populations. Additionally, in the bone marrow above $50 \%$ of stem cells expressed OB-R (Table 2). Our results concern-

Table 1. Comparison of percentage distribution of cell populations in bone marrow and peripheral blood

\begin{tabular}{lccc}
\hline Cell phenotype & \multicolumn{2}{c}{ Median [\%] } & $p$ value \\
& $\left(\mathbf{Q}_{\mathbf{1}}-\mathbf{Q}_{\mathbf{3}}\right)$ & \\
\cline { 2 - 3 } & $\mathbf{B M}$ & $\mathbf{P B}$ & \\
\hline CD33+CD13+ & 92.2 & $\boldsymbol{n}=\mathbf{2 5}$ & \\
\hline CD14+CD4+ & $(71.32-95.23)$ & $(66.56-90.24)$ & NS \\
& 4.76 & 5.31 & NS \\
\hline CD19+CD22+ & $35.92-6.43)$ & $(3.55-8.03)$ & \\
\hline & $(23.78-51.20)$ & $(14.52-27.32)$ & 0.01 \\
\hline CD2+CD5+CD7+ & 34.50 & 48.10 & 0.01 \\
& $(22.2-46.35)$ & $(39.0-55.81)$ & \\
\hline
\end{tabular}

$B M$ - bone marrow; $P B$ - peripheral blood, $Q_{1}-Q_{3}-$ first and third quartile, $n$-number of patients, $N S$ - non significant

Table 2. Comparison of OB-R+ cells percentage in bone marrow and peripheral blood

\begin{tabular}{|c|c|c|c|c|}
\hline \multirow[t]{2}{*}{ Cell population } & \multirow[t]{2}{*}{ Antigen } & \multicolumn{3}{|c|}{$\begin{array}{l}\text { Median OB-R+[\%] } \\
\left(Q_{1}-Q_{3}\right)\end{array}$} \\
\hline & & $\begin{array}{c}\text { Bone marrow } \\
\quad n=11\end{array}$ & $\begin{array}{c}\text { PBL } \\
n=25\end{array}$ & $p$ value \\
\hline Total & & $\begin{array}{c}43.93 \\
(38.80-51.70)\end{array}$ & $\begin{array}{c}38.21 \\
(33.20-45.29)\end{array}$ & NS \\
\hline \multirow[t]{3}{*}{$\mathrm{T}$ cells } & $\begin{array}{c}\mathrm{CD} 2+\mathrm{CD} 5+ \\
\mathrm{CD} 7+\end{array}$ & $\begin{array}{c}8.04 \\
(3.65-12.70)\end{array}$ & $\begin{array}{c}3.67 \\
(2.43-5.78)\end{array}$ & 0.01 \\
\hline & $\mathrm{CD} 2+\mathrm{CD} 4+$ & $\begin{array}{c}11.87 \\
(7.58-19.40)\end{array}$ & $\begin{array}{c}7.93 \\
(5.57-11.06)\end{array}$ & NS \\
\hline & $\mathrm{CD} 2+\mathrm{CD} 8+$ & $\begin{array}{c}37.69 \\
(30.30-59.80)\end{array}$ & $\begin{array}{c}20.74 \\
(7.97-32.63)\end{array}$ & 0.005 \\
\hline $\mathrm{B}$ cells & CD19+CD22+ & $\begin{array}{c}9.53 \\
(5.68-13.80)\end{array}$ & $\begin{array}{c}15.84 \\
(11.88-24.4)\end{array}$ & 0.001 \\
\hline Monocytes & CD4+CD14+ & $\begin{array}{c}90.3 \\
(84.90-94.50)\end{array}$ & $\begin{array}{c}94.23 \\
(85.1-96.30)\end{array}$ & NS \\
\hline Granulocytes & CD33+/CD13+ & $\begin{array}{c}75.78 \\
(62.75-86.40)\end{array}$ & $\begin{array}{c}75.69 \\
(68.4-88.90)\end{array}$ & NS \\
\hline Stem cells & CD34+ & $\begin{array}{c}51.47 \\
(46.50-65.10)\end{array}$ & & \\
\hline
\end{tabular}

$P B L$ - peripheral blood leukocytes; $Q 1$ and Q3 first and third quartile; $n$ - number of patients; NS - non significant 
Table 3. Comparison of percentages of OB-R positive cells in populations of nucleated bone marrow cells and peripheral blood cells

\begin{tabular}{llcc}
\hline Phenotype of compared population & \multicolumn{2}{c}{$p$ value } \\
\hline \% higher & \multicolumn{1}{c}{ \% lower } & BM & PB \\
\hline CD14+CD4+ & $\mathrm{CD} 33+\mathrm{CD} 13+$ & 0.01 & 0.0008 \\
\cline { 2 - 4 } & $\mathrm{CD} 2+\mathrm{CD} 5+\mathrm{CD} 7+$ & 0.0004 & 0.0001 \\
\cline { 2 - 4 } & $\mathrm{CD} 19+\mathrm{CD} 2+$ & 0.0001 & 0.0001 \\
\cline { 2 - 4 } & $\mathrm{CD} 34+0.0001$ & & \\
\hline $\mathrm{CD} 33+\mathrm{CD} 13+$ & $\mathrm{CD} 2+\mathrm{CD} 5+\mathrm{CD} 7+$ & 0.0001 & 0.0001 \\
\cline { 2 - 4 } & $\mathrm{CD} 19+\mathrm{CD} 22+$ & 0.0001 & 0.0001 \\
\cline { 2 - 4 } & $\mathrm{CD} 34+0.0001$ & & \\
\hline $\mathrm{CD} 19+\mathrm{CD} 22+$ & $\mathrm{CD} 2+\mathrm{CD} 5+\mathrm{CD} 7+$ & $\mathrm{NS}$ & 0.001 \\
\hline $\mathrm{CD} 2+\mathrm{CD} 8+$ & $\mathrm{CD} 2+\mathrm{CD} 4+$ & 0.006 & 0.0001 \\
\hline
\end{tabular}

BM - bone marrow; $P B$ - peripheral blood; $N S$ - non significant

ing the CD34+OB-R+ cells are in agreement with the information published earlier [5, 9, 14, 21]. It was demonstrated that leptin is a potent regulator of hematopoiesis, because the addition of leptin to stem cells cultures increased the number of lymphoid, erythroid and myeloid colonies [9, 16]. High percentage of OB-R positive stem cells unable to respond to leptin stimulation may be an advantageous solution for maintenance of proper hematopoiesis.

We have observed the expression of leptin receptors on $\mathrm{B}$ and $\mathrm{T}$ cells derived from bone marrow and peripheral blood. Percentages of OB-R positive lymphocytes in bone marrow and peripheral blood are significantly lower in comparison to respective percentages of monocytes and granulocytes. In bone marrow, percentage of OB-R+ T and B cells was similar whereas in peripheral blood significantly higher percentage of B cells were OB-R+ in comparison to $\mathrm{T}$ cells. Zarkesh-Esfahani et al. [19] have reported much smaller numbers of OB-R positive monocytes and granulocytes ( $12 \pm 4 \%$ and $25 \pm 5 \%$, respectively) and lack of the OB-R in T lymphocytes. The discrepancy between these observations may be caused by two reasons. First of all, different monoclonal antibodies directed specifically against OB-R were used in these studies. They used antibody obtained against the recombinant human leptin receptor extracellular domain, while in our study we have used monoclonal antibody available commercially, that recognizes long isoform of leptin receptor. Secondly, it is necessary to consider different age of the studied subjects, children in our study vs. adults in their group.

In our study the expression of OB-R on T lymphocytes was analyzed considering the expression of CD4 and CD8 antigens. In the both studied tissues the percentage of surface leptin receptor expressing cells was significantly high-
Table 4. Leptin concentration in bone marrow and peripheral blood plasma

\begin{tabular}{lccc}
\hline Plasma & $\boldsymbol{n}$ & BMI range & $\begin{array}{c}\text { Leptin } \\
\text { concentration } \\
(\mathbf{n g} / \mathbf{m l})\end{array}$ \\
\hline $\mathrm{BM}$ & 42 & 1.43 \\
& & $15.2-18.4 \mathrm{~kg} / \mathrm{m}^{2}$ & $(0.99-2.23)$ \\
\hline PB & & 3.26 \\
& & $(2.14-3.88)$ \\
\hline$p$ value & 0.0001 \\
\hline BM- bone marrow; $P B-$ peripheral blood respectively, BMI- body mass index
\end{tabular}

er in the subpopulation of $\mathrm{CD} 2 \mathrm{CD} 8$ in comparison to CD2CD4 lymphocytes.

Lower percentages of OB-R+ cells in these two $\mathrm{T}$ cell subpopulations in peripheral blood were found in comparison to bone marrow, but significant differences was only in subpopulations of CD2+CD8+ T cells.

On the basis of percentages changes in $\mathrm{OB}-\mathrm{R}+\mathrm{T}$ and B-lymphocytes it is possible to suggest that mature B-lymphocytes after passing from bone marrow to peripheral blood gain leptin receptor while CD2CD8 cells exert tendency to opposite reaction. May be it is connected with changes of ratios $\mathrm{T}$ : $\mathrm{B}$ cells in bone marrow and peripheral blood. Because of low number of B cells on periphery in comparison to bone marrow, more B cells expressed leptin receptor. It is in opposite to significantly increased on number of $\mathrm{T}$ cells without of this receptor in peripheral blood.

The observed drop in the number of OB-R+ T cells in peripheral blood limits their ability to respond to increased leptin concentration in blood. It was documented that lepitn is able to induce the activation and the proliferation of human circulating T cells [22, 23]. Moreover, in vitro experiments shown that leptin enhances Th1 proinflammatory cytokine production [18] and suppresses the synthesis of Th2 cytokines. Lower number CD2CD4OB-R+ cells able to bind leptin may be one of a mechanism to maintain inflammatory response under additional control. There is hardly any data on the role of leptin in B-lymphocytes homeostasis in human subjects. Tanaka et al. showed the alteration of B cell development in bone marrow in fasted mice that was characterized by the decrease in pro- $\mathrm{B}$, pre- $\mathrm{B}$ and immature $\mathrm{B}$ as well as the increase in mature $\mathrm{B}$ development [24]. Using B cells isolated from human blood, Agrawal et al. documented for the first time that leptin triggers B lymphocytes to secrete proinflammatory and immunoregulatory cytokines such as IL-6, tumor necrosis factor $\alpha$ (TNF- $\alpha$ ) and IL-10 [12]. Moreover, they have showed that under leptin influence expression of CD25 and HLA-DR on B cells was increased. Leptin may influence only on B cells equipped with specific surface leptin receptor. Higher leptin concentration and number of OB-R pos- 
itive B cells in peripheral blood in comparison to bone marrow created better settings for participation of B cells in inflammatory response in peripheral tissues. Probably, lower number of $\mathrm{OB}-\mathrm{R}+\mathrm{B}$ cells and lower leptin concentration in bone marrow in comparison to peripheral blood protect these cells against leptin-induced apoptosis. In the bone marrow, where B cells develop and maturate, the balance between B cell survival and death have to be maintained, mainly because its disturbances create danger of B cell immunodeficiency or autoimmunity. Recently, it was well documented that leptin increases the expression of Bcl-2 and cyclin D1 in human B lymphocytes [4] and in this way protects of B cells from apoptosis.

Presented results revealed significantly higher leptin concentration in children' peripheral blood than in bone marrow. It is conceivable that low leptin concentration in bone marrow results from its higher cellular consumption. The presence of leptin in bone marrow together with high percentage of stem cells $\mathrm{Ob}-\mathrm{R}+$ and myeloid cells line $\mathrm{Ob}-\mathrm{R}+$ as well as higher percentage of two T cell subpopulations $\mathrm{Ob}-\mathrm{R}+$ than in peripheral blood enhances cell differentiation, proliferation and functional activation [22, 23].

The data presented in this studies revealed that percentages of OB-R+ monocytes and granulocytes in bone marrow and peripheral blood are on comparable level. In contrast, significant difference between bone marrow and peripheral blood was observed when one compare OB-R+T and $\mathrm{OB}-\mathrm{R}+\mathrm{B}$ cell ratios. This may suggest the existence of some regulatory influence of various leptin concentration in studied compartments.

The authors declare no conflict of interest.

\section{References}

1. Fantuzzi G, Faggioni R (2000): Leptin in the regulation of immunity, inflammation and hematopoiesis. J Leukoc Biol 68: 437-446.

2. Zhang Y, Proenca R, Maffei M, et al. (1994): Positional cloning of the mouse obese gene and its human homologue. Nature 372: 425-432.

3. Mantzoros CS (1999): The role of leptin in human obesity and disease: a review of current evidence. Ann Intern Med 130: 671-680.

4. Lam QL, Wang S, Ko OK, et al. (2010): Leptin signaling maintains B-cell homeostasis via induction of $\mathrm{Bcl}-2$ and cyclin D1. Proc Natl Acad Sci U S A 107: 13812-13817.

5. Gainsford T, Willson TA, Metcalf D, et al. (1996): Leptin can induce proliferation, differentiation, and functional activation of hematopoietic cells. Proc Natl Acad Sci U S A 93: 1456414568.

6. Caspar-Bauguil S, Cousin B, Bour S, et al. (2009): Adipose tissue lymphocytes: types and roles. J Physiol Biochem 65: 423-436.
7. Sánchez-Margalet V, Martín-Romero C, Santos-Alvarez J, et al. (2003): Role of leptin as an immunomodulator of blood mononuclear cells: mechanisms of action. Clin Exp Immunol 133: 11-19.

8. Zhao Y, Sun R, You L, et al. (2003): Expression of leptin receptors and response to leptin stimulation of human natural killer cell lines. Biochem Biophys Res Commun 300: 247-252.

9. Bennett BD, Solar GP, Yuan JQ, et al. (1996): A role for leptin and its cognate receptor in hematopoiesis. Curr Biol 6: 1170-1180.

10. Baumann H, Morella KK, White DW, et al. (1996): The fulllength leptin receptor has signaling capabilities of interleukin 6-type cytokine receptors. Proc Natl Acad Sci U S A 93: 83748378.

11. Ghilardi N, Skoda RC (1997): The leptin receptor activates Janus kinase 2 and signals for proliferation in a factor-dependent cell line. Mol Endocrinol 11: 393-399.

12. Agrawal S, Gollapudi S, Su H, Gupta S (2011): Leptin activates human $B$ cells to secrete TNF- $\alpha$, IL- 6 , and IL-10 via JAK2/STAT3 and p38MAPK/ERK1/2 signaling pathway. J Clin Immunol 31: 472-478.

13. Tartaglia LA, Dembski M, Weng X, et al. (1995): Identification and expression cloning of a leptin receptor, OB-R. Cell 83: 1263-1271.

14. Cioffi JA, Shafer AW, Zupancic TJ, et al. (1996): Novel B219/OB receptor isoforms: possible role of leptin in hematopoiesis and reproduction. Nat Med 2: 585-589.

15. Tartaglia LA (1997): The leptin receptor. J Biol Chem 272: 6093-6096.

16. Lam QL, Lu L (2007): Role of leptin in immunity. Cell Mol Immunol 4: 1-13.

17. Mattioli B, Straface E, Quaranta MG, et al. (2005): Leptin promotes differentiation and survival of human dendritic cells and licenses them for Th1 priming. J Immunol 174: 6820-6828.

18. Mattioli B, Straface E, Matarrese P, et al. (2008): Leptin as an immunological adjuvant: enhanced migratory and CD8+ Y cell stimulatory capacity of human dendritic cells exposed to leptin. FASEB J 22: 2012-2022.

19. Zarkesh-Esfahani H, Pockley G, Metcalfe RA, et al. (2001): High-dose of leptin activates human leukocytes via receptor expression on monocytes. J Immunol 167: 4593-4599.

20. Suzukawa M, Nagase H, Ogahara I, et al. (2011): Leptin enhances survival and induces migration, degranulation, and cytokine synthesis of human basophils. J Immunol 186: 52545260.

21. Konopleva M, Mikhail A, Estrov Z, et al. (1999): Expression and function of leptin receptor isoforms in myeloid leukemia and myelodysplastic syndromes: proliferative and anti-apoptotic activities. Blood 93: 1668-1676.

22. Martín-Romero C, Santos-Alvarez J, Goberna R, SánchezMargalet V (2000): Human leptin enhances activation and proliferation of human circulating T lymphocytes. Cell Immunol 199: 15-24.

23. De Rosa V, Procaccini C, Cali G, et al. (2007): A key role of leptin in the control of regulatory $\mathrm{T}$ cell proliferation. Immunity $26: 241-255$.

24. Tanaka M, Suganami T, Kim-Saijo M, et al. (2011): Role of central leptin signaling in starvation-induced alteration of B cell development. J Neurosci 31: 8373-8380. 